\title{
Sensitivity of California Isolates of Uncinula necator to Trifloxystrobin and Spiroxamine, and Update on Triadimefon Sensitivity
}

\author{
T. C. Miller and W. D. Gubler, Department of Plant Pathology, University of California, Davis 95616
}

\begin{abstract}
Miller, T. C., and Gubler, W. D. 2004. Sensitivity of California isolates of Uncinula necator to trifloxystrobin and spiroxamine, and update on triadimefon sensitivity. Plant Dis. 88:1205-1212.

Sensitivities of Uncinula necator to spiroxamine and trifloxystrobin were established by assay of 36 and 35 isolates, respectively, recovered from California grape vineyards in 2002 and increased as single-spore lines for laboratory testing. Twenty-nine single-spore isolates also were evaluated for levels of sensitivity to the fungicide triadimefon to determine if there had been a reversion to sensitivity following the development of resistance in 1986. Although triadimefon use was limited after 1992, other demethylation inhibitor (DMI) fungicides (fenarimol and myclobutanil) were used extensively in California vineyards. For spiroxamine, the sample mean value of the median effective concentration $\left(\mathrm{EC}_{50}\right.$ value) was $365 \mu \mathrm{g} / \mathrm{liter}(95 \%$ confidence interval $[\mathrm{CI}]$ from 251 to $531 \mu \mathrm{g} / \mathrm{liter}$ ) and values were distributed log-normally. The corresponding mean for trifloxystrobin was $12.8 \mu \mathrm{g} / \mathrm{liter}$ bounded by 8.9 to $18.5 \mu \mathrm{g} / \mathrm{liter}$ for the $95 \% \mathrm{CI}$. Statewide, the triadimefon mean $\mathrm{EC}_{50}$ was $8.8 \mathrm{mg} / \mathrm{liter}$, bounded by a 5.3 to $14.5 \mathrm{mg} / \mathrm{liter} 95 \% \mathrm{CI}$, and those values were significantly higher than those obtained in the last assay 12 years earlier. Significant differences in sensitivity of $U$. necator to triadimefon were detected at a regional scale by comparison of mean $\mathrm{EC}_{50}$ values of frequency distributions representative of regions within California, although the relations between those regions were different from the prior survey.
\end{abstract}

Additional keywords: morpholine, QoI, spiroketalamine, sterol biosynthesis inhibitor (SBI), strobilurin

Uncinula necator, the grape powdery mildew pathogen, is a cosmopolitan, sexually crossing population (41). Resistance management for fungicides used to control the pathogen is imperative to preserve their utility. Sampling from subpopulations over time establishes parameters descriptive of sensitivities to particular fungicides for later comparisons. In our laboratory, we have been monitoring U. necator in California for over a decade (36), allowing comparison of sensitivities to some of the more commonly used fungicides. Sensitivities to fungicides vary between geographical regions in California (17).

Spiroxamine or spiroketalamine is a newer sterol biosynthesis inhibitor (SBI) of the morpholine class that gives excellent control of powdery mildews $(8,25)$. Pending its possible registration to control powdery mildew in California vineyards, isolates of $U$. necator were collected from all major production regions and doseresponse was determined. These data will serve as a baseline against which comparisons can be made with respect to the emer-

Corresponding author: T. C. Miller

E-mail: tcmiller@ucr.edu

Accepted for publication 9 June 2004.

Publication no. D-2004-0902-04R

(c) 2004 The American Phytopathological Society gence of resistance in future populations. Currently, no other morpholine fungicides, such as fenpropimorph, tridimorph, or fenpropidin, have been used on this crop in California. Leroux et al. (29) studied activity levels of spiroxamine on the grape bunch rot pathogen, Botrytis cinerea, in France.

Trifloxystrobin, a strobilurin-class fungicide (also known as a QoI fungicide, because it inhibits mitochondrial respiration by binding to the Qo site, or outer, quinone-oxidizing pocket; 15), was registered in California for powdery mildew control in grapevine in 2001. Wong and Wilcox (49) reported the first regional survey of $U$. necator sensitivity to this material from samples collected from New York state. Sensitivities to the fungicide in field isolates of $U$. necator have been reported by Reuveni (40); however, because the collections tested were not from single spores, the measures represent unknown diversity within the Israeli subpopulation of $U$. necator in the Golan region. In California, other QoI fungicides used on grape include kresoxim-methyl, pyraclostrobin, and azoxystrobin.

Abandoned by growers due to fungicide resistance and the introduction of competitor products, triadimefon (Bayleton 50DF) was the first demethylation inhibitor (DMI) fungicide used for control of grape powdery mildew in California. Triadimefon was introduced into California vine- yards in 1982. Resistance was suspected in 1985 and documented in 1986 (36). It was widely used and misused, which probably hastened resistance development. Subsequently, myclobutanil, fenarimol, and, later, triflumazole and tebuconazole were used. Cross-resistance was suspected early with these other DMI fungicides and triadimefon, and was demonstrated later $(17,52)$. In spite of the decline in growers' use of triadimefon in California for most grapevine powdery mildew control since 1993, California subpopulations of $U$. necator have been exposed regularly to the aforementioned DMI fungicides in the years since 1989.

Initial objectives for this study included the first measures of the sensitivity of $U$. necator to both spiroxamine and trifloxystrobin in California, against which comparisons can be made in the future with respect to the emergence of resistance. For the morpholine, this will be a true baseline and, for the latter, the first measure specific to trifloxystrobin, although other QoI fungicides had been used in this crop for 5 years when sampled. In the present study, we report the results of the first California regional survey of $U$. necator's sensitivity to trifloxystrobin and spiroxamine. Another objective tested the hypothesis that there would be no change in sensitivity of California subpopulations of the grape powdery mildew pathogen to triadimefon over the 12 years of limited use or, alternately, that the level of sensitivity in $U$. necator would have reverted to preresistant levels.

\section{MATERIALS AND METHODS}

Isolate collection and maintenance. New isolates of $U$. necator were collected throughout California during the 2002 growing season from commercial vineyards, including those producing table grapes, raisins, and wine grapes. In all, 39 isolates were increased and assayed successfully, from which subsets of 29, 35, and 36 isolates were evaluated for sensitivity to the fungicides triadimefon, trifloxystrobin, and spiroxamine, respectively. The collections were analyzed by production regions to correspond with prior studies (17) and were designated North Coast and Napa region; Central Coast; North San Joaquin and Sacramento Valley; and South San Joaquin Valley. When multiple isolates were taken from the same vineyard, collections were made from locations as distant as practicable, sometimes with greater than 
$0.5 \mathrm{~km}$ of separation. Infected leaves were either rub transferred to clean, susceptible grapevine seedlings on site or collected and brought back to the laboratory for rub transfer. The highly susceptible cv. Carignane was used for all of the experimental grape material used for maintenance and testing of the collected subcultures and single-spore isolates. Inoculated plants were placed in individual plastic tubes to avoid cross contamination, either on site or immediately after rub transfer in a laboratory laminar flow hood.

Single conidia or individual chains of conidia were transferred from these mass transfers in a laminar flow hood (to avoid cross contamination of isolates) to establish infections on 11-mm-diameter leaf disks excised from surface-disinfested, mildew-free Carignane grape seedlings. Surface disinfestation was by immersion of whole leaves for $30 \mathrm{~s}$ in $50 \%$ aqueous ethanol, followed by drying in a laminar flow hood before excision of leaf disks using a sterile cork borer. A single camel hair from an artist's paintbrush was used to transfer individual conidia or occasional single conidial chains to the disk, working with the aid of a dissecting scope at $\times 45$ magnification. The disks were incubated for 7 to 21 days (at ambient laboratory conditions in plastic chambers as described below) before rub transfer to mildew-free 4- to 6-week-old seedlings. These seedlings were maintained in tubes in a growth chamber at $25^{\circ} \mathrm{C}$ with day and night cycles of 14 and $10 \mathrm{~h}$, respectively, and $65 \%$ relative humidity $(\mathrm{RH})$ and were shaken periodically to distribute new conidia to the rest of the plant. Conidia from these isolates were used for the inoculum-to-assay dose response.

Leaf disk bioassay. Higher replication number was achieved than that afforded by whole leaf assays (19) by using our previously described procedures (52), slightly modified to include surface disinfestation of the grape leaf material prior to use (10) as described above. Each increased monoconidial isolate was tested for sensitivity to the fungicide by depositing spores on treated leaf disks placed arbitrarily within a spore-settling tower. A completely randomized design was used. Portions of the analysis were taken from a balanced subset of the treated disks, and others were investigated differently, as described below. These were incubated for 10 days on a lab bench and the extent of infection quantified by the area affected to determine the dose response.

Each fungicide was tested against $U$. necator for dose response by challenge inoculations of treated leaf disks which had been immersed in serial dilutions of the test fungicides. Technical grade trifloxystrobin and spiroxamine (Bayer Corporation, Kansas City, MO) first were dissolved in acetone and then serially diluted in water to attain the desired concentra- tions. The concentration of acetone in the highest dose tested never exceeded $0.5 \%$ (wt/wt). Triadimefon was tested as the formulated material Bayleton 50DF, which also was serially diluted in water. Fungicide concentrations tested varied over the course of the study, especially when particularly insensitive or sensitive isolates were evaluated, but, in general, ranged from three to four orders of magnitude, divided into geometric intervals of either the base of the natural logarithm, $e$, or the square root of 10 . Only the fully expanded leaves from positions 2 through 5 counting back from shoot tips of Carignane grapevines were used. These were surface disinfested as described above, then placed in the fungicidal test solutions for $30 \mathrm{~min}$. Surface-disinfested disks similarly prepared but not immersed in fungicidal solutions were used as the nontreated controls. The disks were removed and placed in a laminar flow hood until just dry. Finally, they were moved to 60 -mm-diameter petri dishes, where they were placed adaxial surface up on two layers of Miracloth (Calbiochem Corp., San Diego, CA) over two layers of paper towel moistened with $0.75 \mathrm{ml}$ of water. All steps in preparation of these testing arenas were carried out aseptically.

Leaf disks were inoculated using a spore-settling tower (39). Leaves with sporulating colonies of the single-spore isolate lines were placed in a wire mesh cage near the top of the tower. Spore deposition and germination were monitored with microscope slides placed at the base of the settling tower, adjacent to the petri dishes containing the leaf disks. The inoculated disks in petri dishes were removed from the tower and the lids were replaced. They were placed in closed plastic chambers (clear, 20-by-14-by-10-cm polystyrene boxes with tight-fitting tops) on plastic supports above a water reservoir so as to maintain a high $\mathrm{RH}$ atmosphere. The microscope slides were incubated similarly overnight or longer, and spore density and germination percentages were determined using a compound microscope. All test doses of the studied fungicides were placed in separate containers to avoid potential interference from the vapor phase of the test fungicides. The infections were allowed to develop for 10 days at ambient laboratory conditions $\left(26 \pm 1^{\circ} \mathrm{C}, 12 \mathrm{~h}\right.$ of fluorescent lighting). Determination of area infected was by visual estimation of colony area (as defined by observable mycelium) aided by dissecting microscope at $\times 45$ magnification.

Full replication of doses tested always included 21 to 24 replicated test disks per dose at inoculation, but attrition due to incidental contamination reduced these numbers by the assay rating at 10 days post inoculation. Most inoculations of single-spore isolate lines were tested at least twice, with intervals greater than 10 days between experimental runs. However, some single-spore isolate lines perished before an additional run could be performed. Data collected from the fully replicated assays of these isolates was included in portions of the data analysis as described below.

Data analysis. Leaf disks were the experimental units. For severity analysis, percent colony growth (relative to growth on nontreated disks) was regressed on $\mathrm{ln}$ transformed fungicide concentration (Excel; Microsoft, Redmond, WA). Only the linear portions of the response were used to estimate median effective concentration $\left(\mathrm{EC}_{50}\right)$ values by the formula $\mathrm{EC}_{50}=e^{([50-\mathrm{b}] /-\mathrm{m})}$ from the regression $y=m \ln$ (concentration) $+b . \mathrm{EC}_{50}$ values are estimates by either severity or incidence, and were introduced conceptually to accommodate suppression rather than lethality when Trevan introduced the median lethal dose $\left(\mathrm{LD}_{50}\right)$ concept (44). Fits where $P>0.5$ were discarded. All data from individual disks were collected (usually 7 to 24 leaf disks surviving to 10 days/test concentration), but only the highest $U$. necator growth responses from the 4 disks with the greatest powdery mildew growth were used for severity analysis. All surviving leaf disks with or without mildew colonies were used to determine disease incidence for incidence analyses. The presence of a single conidiophore and conidium on the inoculated material was sufficient to be classified as infected.

Individual experimental runs provided data for a single-spore line of $U$. necator growth response from 7 to 24 disks for each of 7 to 9 fungicide concentrations tested and the nontreated control. All tests began with 21 to 24 leaf disks per concentration tested, but incidental airborne contamination in the spore-inoculating tower reduced the number of leaf disks surviving until 10 days post inoculation. The inverse prediction technique outlined in Geng (12) was used to determine upper and lower confidence intervals for individual $\mathrm{EC}_{50}$ estimates, because variation in the ordinate (estimates of confidence in the $\mathrm{EC}_{50}$ ) was necessary for analysis of single-spore isolate lines that perished before repeated runs could be performed.

Fungicide Resistance Action Committee (FRAC) guidelines (27) recommend probit analysis; therefore, percent severity data for each fungicide concentration (from the means of the four highest mildew growth response replicates) were probit transformed (4). The derivation of probit analysis was premised upon binomial statistical distributions (11); therefore, the data also were analyzed by incidence (infection or no infection) of the test leaf disks. Percent incidence (from all replicates, $n \geq 4$, usually 14 to 24 ) was probit transformed before estimating $\mathrm{EC}_{50}$ values.

Estimates of $\mathrm{EC}_{50}$ values of single-spore isolates were tabulated into geometrically 
spaced sensitivity classes, or frequency distributions. These were checked for descriptive statistics, and low-end "outside" values (less than the first quartile, or lower "hinge", by greater than 1.5 times the spread between the first and third quartile of the data sets) were removed from the data sets before analysis by Tukey's procedure (45). Isolates were grouped into classes based upon the $\mathrm{EC}_{50}$ values estimated, according to Sturges' rule (12) for the newer fungicides, and to correspond with classes used before (17) for triadimefon. Although the exact sampling locations differed from the prior triadimefon survey, the data collection and analysis techniques (i.e., single-spore isolates from vineyards throughout all four major viticultural regions, severity data from leaf disk challenge assay, and probit conversion of percent severity data) were adhered to again for meaningful comparison. The historical data sets also were analyzed again for descriptive statistics and, in a few instances (i.e., for the distributions representing the North San Joaquin and Sacramento Valley, and also for the cumulative distribution for the whole state), the low-end outliers were removed according to Tukey's procedure (45) as described above. Estimated $\mathrm{EC}_{50}$ values were pooled into the same classes used for the last survey (tenth root of 10 intervals) for easy application of Kolmogorov-Smirnov testing. Subsets by region of collection were analyzed for comparisons. Individual frequency distributions for each region were reconfigured into cumulative frequency distributions, after which confidence bands were calculated about their characteristic log-normal sigmoid depictions. This allowed application of the Kolmogorov-Smirnov test statistic for hypothesis testing. When the $D_{\text {critical }}$ test statistic was exceeded, the frequency distributions compared were determined distinct (50).

Lest influence of analytical method on interpretation of data hinder comparison of surveys 12 years apart in time, the data sets were analyzed by various aggregations to investigate analytical method effects upon estimates of the frequency distribution statistics of coefficients of variation, mean determinations, and confidence intervals. Frequency distributions were composed of either all experimental runs or only the geometric means derived from repeated runs. Also, frequency distributions were constructed from both severity and incidence data. The distributions analyzed (Table 1; Fig. 1) are from less than the total data collected, with low-end outliers removed by Tukey's procedure (45) but high-end outliers retained.

\section{RESULTS}

$\mathrm{EC}_{50}$ values for single-spore isolates were log-normally distributed for spiroxamine and trifloxystrobin. Means and confidence intervals for the entire state are presented (Table 1). This survey will serve as the reference from which to measure future deviations indicating the development of fungicide resistance. For example, if a future sampling of trifloxystrobin sensitivity indicates the statewide mean $\mathrm{EC}_{50}$ value is $29 \mu \mathrm{g} / \mathrm{liter}$, there is $95 \%$ confidence that those results did not occur by chance when the subpopulation sampled in fact had the same sample mean as at this survey, whether measured by probits of severity or incidence, or by single assays or means of repeated assays of the same single-spore line. This future hypothetical result would indicate that, in fact, the level of sensitivity lessened, indicating a shift to more resistant individuals in the California subpopulation. Similarly, a future measure of a statewide mean $\mathrm{EC}_{50}$ value of 850 $\mu \mathrm{g} / \mathrm{liter}$ for spiroxamine would indicate a probable shift toward more resistant isolates of $U$. necator.

Trifloxystrobin was active at very low levels, with mean $\mathrm{EC}_{50}$ values for the state below $21 \mu \mathrm{g} /$ liter by any assay analysis. The highest $\mathrm{EC}_{50}$ value estimated was 343 $\mu \mathrm{g} / \mathrm{liter}$, but no isolate showed any growth at $1 \mathrm{mg} /$ liter, suggesting $\mathrm{LD}_{100} \leq 1 \mathrm{mg} /$ liter for the California subpopulation. In one data set used for analysis (that is, the data set comprising the geometric means of repeated runs of isolates using the probit of the percent incidence), the highest value estimated was determined to be an outlier by Tukey's procedure, but retained for construction of confidence intervals and mean determination. This is indicated by an underline of the value in Table 1. Three higher individual measures were made from other isolates in the overall collection of the incidence data.

Spiroxamine also was active at very low amounts, with the statewide average $\mathrm{EC}_{50}$ value estimated between 365 and 571 $\mu \mathrm{g} / \mathrm{liter}$, depending upon method of analysis. It was noted that two isolates had individual runs where the $\mathrm{EC}_{50}$ values were estimated near 17 and $20 \mathrm{mg} / \mathrm{liter}$, but overall means of three and two repeated assays of the same isolates yielded overall geometric means of the $\mathrm{EC}_{50}$ values of 4 and $9 \mathrm{mg} / \mathrm{liter}$, respectively, by probits of incidence data. The severity analysis of these same isolates yielded 2.4 and 0.5 $\mathrm{mg} / \mathrm{liter} \mathrm{EC}_{50}$ values, respectively, as geometric means. There is a portion of the unexposed subpopulation of $U$. necator in California with a high natural tolerance to this unreleased material compared with the overall statewide mean.

Analytical method was compared for the same data sets. (Table 1). Inspection of different analyses revealed the impact of methodology upon estimates of statistics concerning the California subpopulation of $U$. necator. Analysis of incidence data determined a higher tolerance level for the pathogen subpopulation for each fungicide than did analysis based upon measure of severity, and also reduced the coefficient of variation in five of six comparisons; that is, three fungicides times two types (severity versus incidence) of assay. Analysis of the geometric means of repeated runs versus

Table 1. Comparison of median effective concentration $\left(\mathrm{EC}_{50}\right)$ values based upon disease severity and incidences for three fungicides for isolates of $U n$ cinula necator collected in California, and impact of data collection methodology upon analysis of dose-response to fungicides

\begin{tabular}{|c|c|c|c|c|c|c|c|c|c|c|}
\hline \multirow[b]{2}{*}{ Fungicide, analysis $^{\text {a }}$} & \multicolumn{5}{|c|}{ Severity } & \multicolumn{5}{|c|}{ Incidence } \\
\hline & $n^{\mathbf{b}}$ & $\mathrm{EC}_{50}{ }^{\mathrm{c}}$ & Ranged $^{d}$ & 95\% CI & $\mathrm{CV}^{\mathrm{e}}$ & $n$ & $\mathbf{E C}_{50}$ & Range & $95 \% \mathrm{CI}$ & CV \\
\hline \multicolumn{11}{|l|}{ Trifloxystrobin } \\
\hline All reps & (76) 74 & 12.8 & (0.03-) $0.23-188$ & $8.9-18.5$ & 62.2 & 75 & 14.3 & $0.03-343$ & $9.8-20.8$ & 61.1 \\
\hline Geometric means & (35) 33 & 13.7 & (0.03-) 1.02-144 & $9.0-20.7$ & 44.7 & (35) 31 & 20.5 & $(0.35-) 3.7-\underline{154}$ & $14.6-28.9$ & 30.6 \\
\hline \multicolumn{11}{|l|}{ Spiroxamine } \\
\hline All reps & (75) 73 & 365 & $(0.45-) 3.50-5,070$ & $251-531$ & 27.2 & (70) 67 & 571 & $(1.28-) 13-19,607$ & $391-834$ & 24.5 \\
\hline Geometric means & (36) 33 & 461 & $(0.45-) 27.8-5,070$ & $297-715$ & 20.1 & (36) 35 & 498 & (1.28-) $9.00-9,316$ & $292-849$ & 25.0 \\
\hline \multicolumn{11}{|l|}{ Triadimefon } \\
\hline All reps & 66 & 8.8 & $0.07-305$ & $5.3-14.5$ & 93.7 & 66 & 11.5 & $0.13-386$ & $7.0-18.6$ & 80.9 \\
\hline Geometric means & 29 & 9.4 & $0.08-186$ & $4.6-19.4$ & 84.8 & 29 & 12.8 & $0.63-204$ & $6.7-24.6$ & 67.3 \\
\hline
\end{tabular}

${ }^{a}$ Data set considered consisted of all replications recorded, or geometric means derived from them (two to three repeat tests).

${ }^{\mathrm{b}}$ Number of values in data set considered to determine means, ranges, confidence intervals (CIs) and coefficients of variability (CVs) following in row. Number in parentheses includes full set before removing outliers by Tukey's method.

${ }^{\mathrm{c}}$ Mean $\mathrm{EC}_{50}$ values = concentration of trifloxystrobin or spiroxamine in micrograms per liter or triadimefon in milligrams per liter effectively suppressing half the growth response (probit of percent area for severity or probit of percent incidence) of the pathogen.

${ }^{\mathrm{d}}$ Low to high values used to determine means of distributions. Lowest end of outliers in parenthesis not included in analysis. High end outlier underlined but included in analysis.

${ }^{\text {e }} \mathrm{CV}$ by ratio of geometric descriptors (i.e., arithmetic values based upon back-transformation from geometric values used for analysis). 
analysis of all replicated runs from which those means were derived also lowered the coefficient of variation and raised the estimates of population mean $\mathrm{EC}_{50}$ values in five of six comparisons; that is, three fungicides times two types (all replicated runs versus geometric means of replicated runs) of assay. It appears that the price of precision comes at higher determinations for population means using this testing method.

Log-normal, unimodal distributions of sensitivities are shown for the California subpopulations for trifloxystrobin and spiroxamine (Fig. 1). The histograms provided exclude the lowest values removed as outliers as described above. The class intervals were determined by considering the range of values to be spanned for all four analyses. These are typical for the frequency distributions of sensitivities to new materials in a pest population, although trifloxystrobin has been in use for 2 years.

Triadimefon sensitivity was compared with historical data (Fig. 2). KolmogorovSmirnov testing revealed significant differences from the last evaluations. Subpopulations sampled from the North Coast and Napa region and the North San Joaquin and Sacramento Valley in 2002 were significantly more resistant than those sampled from those regions in 1990 (99\% confidence level, Kolmogorov-Smirnov test). The overall California population also was significantly more resistant by the same analysis (99\% confidence level). The probability value that the distribution of $\mathrm{EC}_{50}$ values describing the Southern San Joaquin Valley region collected in 2002 differed from the subpopulation sampled there in 1990 was 0.109 ; it is noteworthy that such results would occur by chance only one of nine times had these samplings, in fact, not differed. In all regions tested, the ranges of $\mathrm{EC}_{50}$ values were greater than in 1990. In all regions tested except for the North San Joaquin and Sacramento Valley, the measured $\mathrm{EC}_{50}$ values spanned a greater range, at both the low and high end, than measured at last sampling. This is not shown for the North Coast and Napa region (Fig. 2), because a low-end outlier $\left(\mathrm{EC}_{50}\right.$ value $=0.079$ $\mathrm{mg} / \mathrm{liter}$ ) was removed from the data set before analysis.

\section{DISCUSSION}

Efforts in data collection in the future will yield better fidelity with less time. Comparison of fungicide data sets revealed consistent patterns that are instructive. The testing method of challenge inoculation of treated leaf disks in this pathosystem yielded reproducible results with precision suitable to detect the emergence of resistance to the newer fungicides in the future. In comparing the assay analytical methods, it has been determined that the collection of incidence data rather than severity data narrows the range of the CIs (relative to the means determined), at the price of higher determinations of mean $\mathrm{EC}_{50}$ values for the frequency distributions considered.
This is reflected in lower coefficients of variability (CVs), determined from arithmetic ranges back-transformed from the geometric (logarithmic) testing intervals. Practically, this greatly reduces the assay evaluation time in the future; microscopic examination of an inoculated leaf disk need only determine infection or not, rather than extent of severity. This could reduce data evaluation time by an order of magnitude, allowing greater numbers of samples to be processed in a set time frame. Although, in all likelihood, the means of the frequency distributions determined will be higher, as a comparative technique across years the assay of incidence will take less time, and be just as fit for detection of emerging resistance. Similarly, whenever possible, calculation of the geometric mean of $\mathrm{EC}_{50}$ values from multiple assays of the same single-spore isolate will further reduce CVs and narrow the CIs. The assay method, by whatever analysis, will aid in the establishment of single, discriminatory dose testing for detection of potentially resistant individuals in the (sub-) population sampled. Identical data sets provided different determinations of $\mathrm{EC}_{50}$ values that were analysis dependent (Table 1). The resolution of the testing system coupled with knowledge of the limits imposed by analytical method chosen will allow detection of the more gradual (qualitative) development of resistance in the future. The comparison of the several available analyses shows the tradeoffs between accuracy, precision, and effort.

Trifloxystrobin

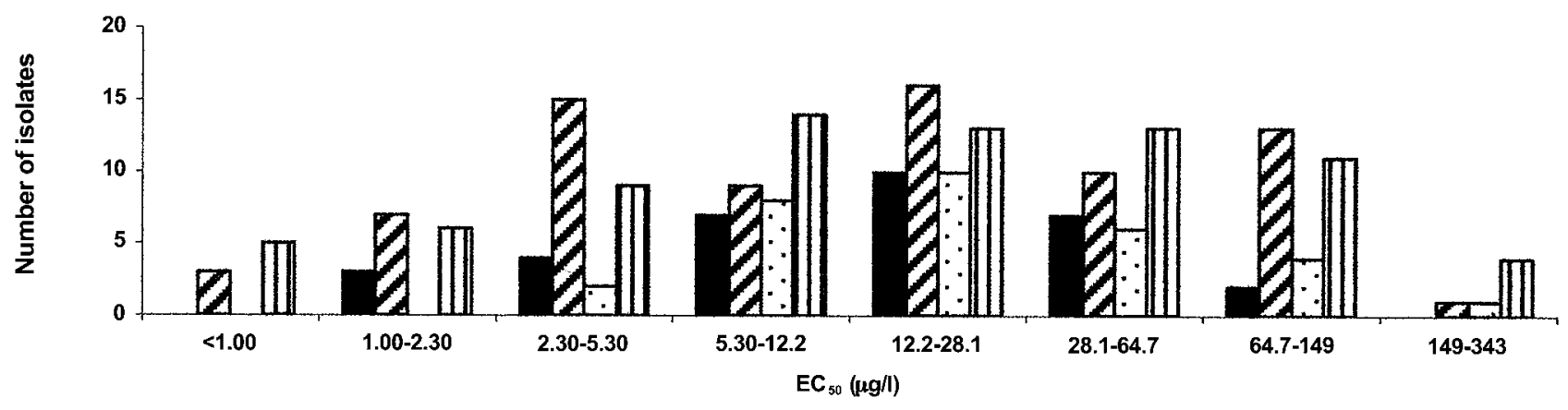

Eeverity - geometric means

Severity - all reps

DIncidence - geometric means

DIncidence - all reps
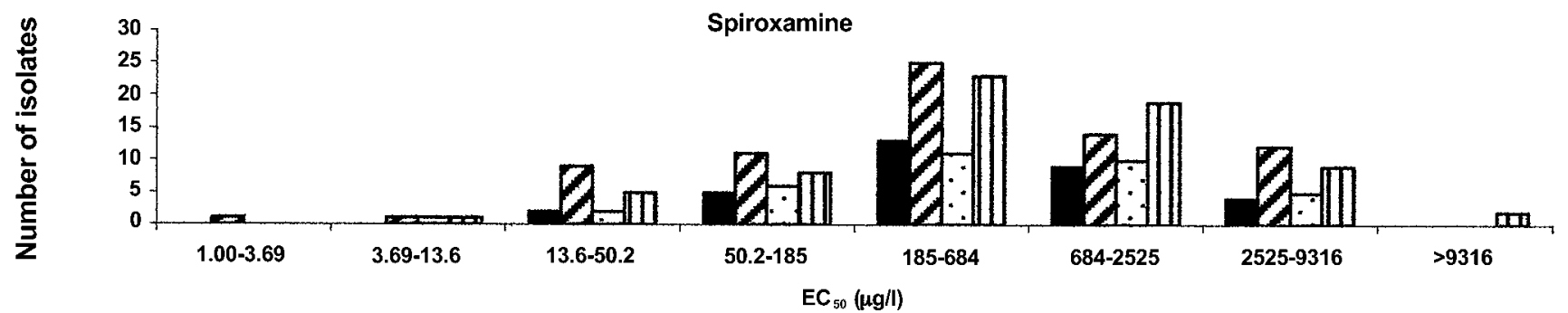

Fig. 1. Population frequency distributions for median effective concentration $\left(\mathrm{EC}_{50}\right)$ values of Uncinula necator, the grape powdery mildew pathogen, with respect to trifloxystrobin ( $n=33$ geometric means from 75 repeated runs, low-end outliers removed) and spiroxamine $(n=35$ geometric means from 75 repeated runs, low-end outliers removed). Four methods of analysis yield four similar log-normal distributions shifted slightly to greater or lesser values for the same assays. 

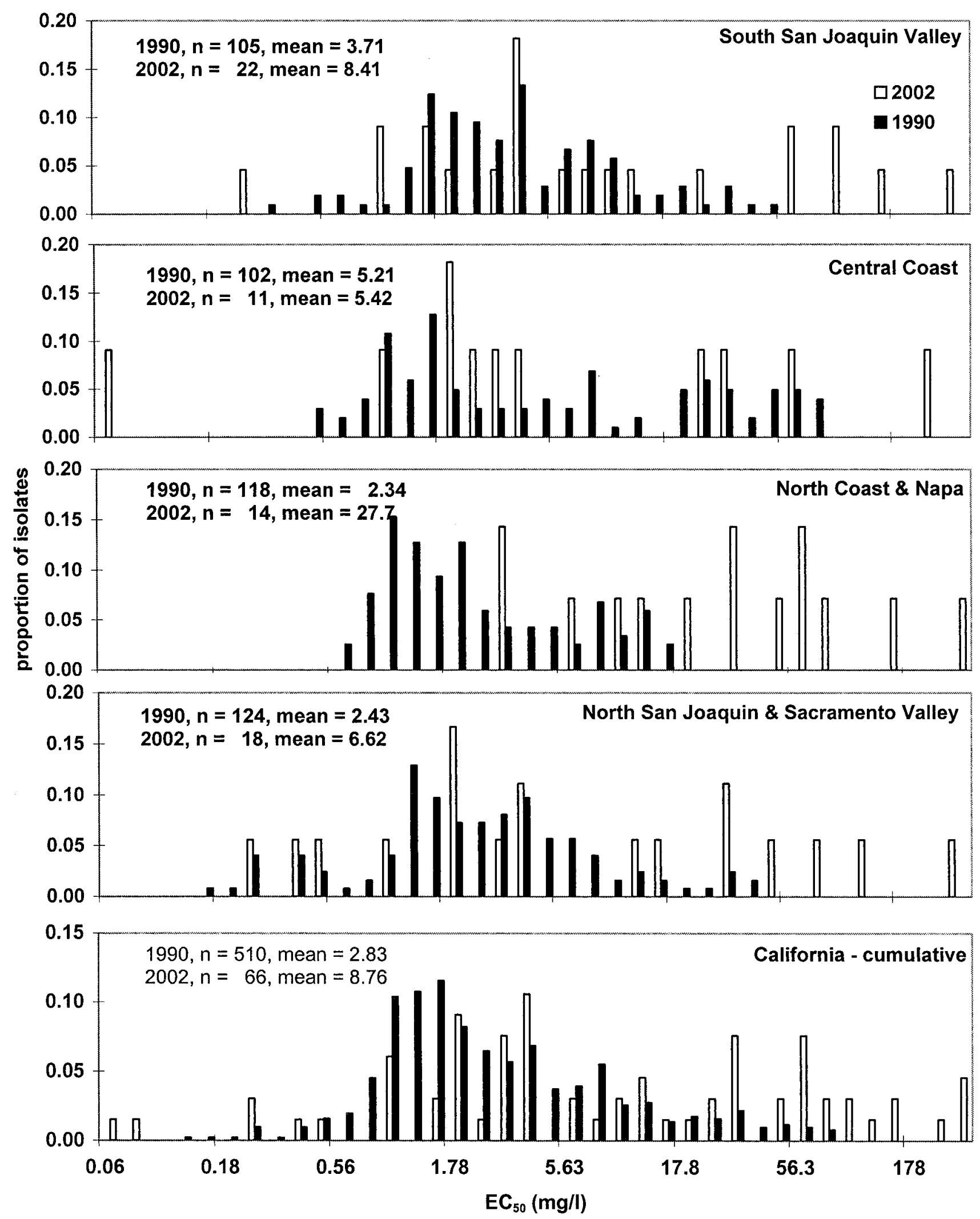

Fig. 2. Frequency distributions of sensitivity to triadimefon of Uncinula necator population in California. Categories are binned median effective concentration $\left(\mathrm{EC}_{50}\right)$ values for triadimefon in milligrams per liter determined by dose-response testing of single-spore isolates from collections throughout all major viticultural regions. Black columns were determined in 1990 (Gubler et al., 1996). White columns were determined in 2002. Significantly more resistant subpopulations were detected in 2002 than in 1990 in the North Coast and Napa regions, the North San Joaquin and Sacramento Valley region, and in the cumulative measure of all regions of California. 
Regarding trifloxystrobin, the distribution of sensitivities in the population of $U$. necator were similar to those measured in New York (49). Depending upon analysis, the overall population mean $\mathrm{EC}_{50}$ for California ranged from 12.8 to $20.5 \mu \mathrm{g} / \mathrm{liter}$ compared with the New York population mean of $15 \mu \mathrm{g} /$ liter. The range of $\mathrm{EC}_{50}$ values measured in this study, again dependent upon analysis, varied from a low of $0.03 \mu \mathrm{g} /$ liter to a high of $343 \mu \mathrm{g} / \mathrm{liter}$ compared with a range of 5.8 to $52 \mu \mathrm{g} / \mathrm{liter}$ reported by Wong and Wilcox (49). Direct comparison of the two studies is not possible because different techniques were used. However, the overall sample means determined were comparable. Our detection of isolates representing significantly higher tolerance to trifloxystrobin is both later in time (2002 versus 1999 collection) and geographically distinct and follows 1 year of trifloxystrobin use and 5 years of QoI fungicide use in California.

Now that so many strobilurin fungicides have come to market, cross resistance is a concern among QoI fungicides (14). Azoxystrobin was commercially available to California grape production in the 1997 season, followed in 2000 by kresoximmethyl, then trifloxystrobin in 2001. Most recently, pyraclostrobin became available in 2003. Field resistance to QoI fungicides already has been confirmed in many crops (3). Trifloxystrobin resistance most recently has been reported in the cucurbit powdery mildew fungus $(33,34)$, confirming results portending this likely eventuality when cross resistance between kresoxim-methyl and azoxystrobin was detected nearly immediately after their introduction for control of this pathogen in Japan (22). Similarly, cross resistance between trifloxystrobin and other QoI fungicides has been documented in gray leaf spot in turf $(2,24,47)$, apple scab $(28,43)$, black Sigatoka $(7,42)$, and where first introduced for cereal powdery mildew and other foliar pathogen control (6). What is instructive from review of these reports and studies is that resistance on the order of magnitude has often linked to known point mutations where pathogens proved insensitive to as high as 10 or even 100 $\mathrm{mg} / \mathrm{liter}$ trifloxystrobin. Comparatively, our findings of the most insensitive isolate of $U$. necator with an $\mathrm{EC}_{50}$ value of 0.3 $\mathrm{mg} / \mathrm{liter}$ seems nothing on the order of these quantitative shifts, and of insufficient magnitude overall to indicate a start toward qualitative resistance. Interestingly, Wong and Wilcox (49) did record a moderate correlation between sensitivities of $U$. necator to the QoI fungicide azoxystrobin and the DMI fungicide myclobutanil in their 1999 survey of isolates from New York state vineyards; a phenomenon more highly pronounced in a selected subpopulation receiving six myclobutanil applications than in the subpopulation sampled at large. The presence of four members of the QoI cross-resistance group in a single crop in California indicates close monitoring of the potential development of resistance is prudent to prevent disease control failure. The most current recommendations (November 2003) of the QoI working group of the North American Fungicide Resistance Action Committee (NAFRAC) for vines are a maximum of two sequential applications of QoI-containing fungicides followed by two or more applications of fungicides from a different resistance class. The most current resistance management guidelines for all fungicides at risk globally can be found online at the FRAC website.

An overall mean $\mathrm{EC}_{50}$ value of 365 to $571 \mu \mathrm{g} / \mathrm{liter}$ (depending upon analysis) was determined for the California population of $U$. necator to spiroxamine. There are no cross-resistance risks currently in use in grape in California. Inhouse studies by Bayer AG (Germany) acknowledge a geographical pattern of sensitivity to spiroxamine in the Blumeria graminis f. sp. tritici subpopulation of northern parts of Central Europe corresponding to the reduced sensitivities developed to the competitor morpholines fenpropidin and fenpropimorph, but also claim no cross resistance with DMI and QoI fungicides (26). Piperalin, a piperidine-type fungicide, considered along with morpholines in the same cross-resistance class, is registered for ornamental usage, with 1.15 metric tons applied in California in 2002 (1), primarily in the greenhouse flowers and their transplants. Dodemorph, another fungicide of the class, previously was used at these same sites, but was withdrawn in 1993.

The morpholine class of SBI fungicides shows cross resistance among its own members $(5,9,38)$, but only with any DMI fungicides as a result of laboratory-induced mutations $(31,35)$. These mutations indicate that multiple modes of resistance probably are acting in concert (48), and the issue of multidrug resistance (MDR) has surfaced with respect to this class in medicine, specifically concerning Candida albicans. In one study, clinical isolates resistant to azole antifungal agents overexpressed the ABC-transporter genes CDR1 and CDR2, which made the mycotic pathogen less susceptible to the morpholine-derivative amorolfine (46). In earlier work, mutant strains resistant to either a triazole, an imidizole, or a morpholine showed cross resistance between these classes of fungicides (20). The MDR phenotype has been described in Botrytis cinerea mutants that exhibit cross resistance to unrelated chemicals (30), and linked convincingly to another ATP-binding cassette (ABC) transporter BcatrD (18). The role of these ABCs involved in toxin efflux potentially explain the phenomena of cross resistance between fungicides, and might well be the phenotypi- cally dominant effectors in a suite of detoxification mechanisms in a given pathogen. Additional references supporting the role of $\mathrm{ABC}$ transporters with respect to DMI resistance can be found in the review by Gisi et al. (14). As noted by Georgopoulos (13), mutant genes at different loci are not additive but, rather, that with the greatest effect is epistatic over other genes affecting that particular sensitivity. The implication is that multigenic and monogenic mechanisms of resistance are easily masked under the response to the phenotypically dominant effect (i.e., resistance to a fungicide). However, the morpholine class has been performing adequately in cereal powdery mildew and rust control in Europe, with no reports of failure at field level when used according to label, according to the FRAC working group on SBI fungicides which met recently (November 2003), in Frankfurt, Germany. In the same meeting, they reported no issues for morpholine fungicides in grape powdery mildew control in 2003. Morpholine fungicides are recognized as resistance management options for alternation or mixtures with DMI fungicides $(23,32,37)$ and an early study found morpholines exhibited negative cross resistance with benzimidazoles in some cases (21).

Even though the use of triadimefon for grapevine powdery mildew control in California has declined to near absence since our last survey, the target population of the pathogen has become more resistant than in 1990. Decreased sensitivity in the statewide subpopulation of $U$. necator does not support the hypothesis that reversion to sensitivity might occur with the removal of selection pressure. Arguably, other DMI fungicides have maintained selection pressure. Only 0.32 metric tons of triadimefon were used in California grape and 0.79 metric tons in all crops combined in 2002. Statewide, the 1990 survey occurred when 13 metric tons of triadimefon were applied in grape statewide, a number that climbed to over 28 metric tons in 1991, to peak at over 57 metric tons in grape alone in 1992 (1); therefore, the last survey was a glimpse of a subpopulation before maximal selection pressure had been applied.

An immediate success, triadimefon quickly lost its market in grape following its introduction to California vineyards. Control failures in the field were most severe in the coastal production areas in 1985, where cooler conditions favored disease development and cleistothecia played an important role in the disease cycle. In 1986, cool temperatures statewide resulted in large pathogen population increase and reports of resistance statewide. Isolates with higher $\mathrm{EC}_{50}$ values were able to infect seedlings treated with the most commonly used field rate (triadimefon at $0.114 \mathrm{~kg} / \mathrm{ha}) 7$ to 10 days earlier than isolates with lower $\mathrm{EC}_{50}$ values (36). The only 
control problems observed in 1987 and 1988 were along the cooler coastal production areas, where production of cleistothecia is more common. Temperatures were higher than normal statewide in 1987 and 1988, which likely helped suppress the disease in the inland production regions (51). Large-scale disease losses occurred again in 1989 and 1990. Environmental conditions influenced latency and, consequently, the number of generations exposed to selection pressure $(16,51)$. Resistant isolates overwintered as ascospore subpopulations and increased in frequency over the course of a season in conidial subpopulations subjected to continued use of DMI fungicides (17).

In reviewing the relative levels of sensitivity to triadimefon among the regions (Fig. 2), it is apparent there have been shifts. The region of the central coast was of particular interest, because this is the location characterized by the highest regular production of cleistothecia. It offers, as well, the most favorable environmental conditions, overall, for the pathogen. Observed $\mathrm{EC}_{50}$ values in 2002 covered a broader range than in 1990, when its subpopulation was characterized as the most resistant of the regions surveyed; however, upon review in 2002, this was no longer so. The predominantly wine grape-producing regions of the north coast and Napa had the most resistant individuals sampled from those regions. The North San Joaquin and Sacramento Valley region, which also is devoted predominantly to wine grape production, also joined the Napa and North Coast region in statistically significant greater resistance to triadimefon. These findings suggest that the costs of maintaining resistance to triadimefon are not sufficient to dispense with this phenotype from the studied subpopulations of $U$. necator in the virtual absence of triadimefon. Given the extensive documentation of cross resistance $(17,52)$ among DMI fungicides, this was not unexpected, although now experimentation validates conjecture.

\section{ACKNOWLEDGMENTS}

We thank L. Fought, W. D. Scott, and J. Bloomberg of Bayer for their generous support; and S. Geng, Professor, Department of Agronomy and Range Science, University of California, Davis, for helpful statistical consultations.

\section{LITERATURE CITED}

1. Anonymous. Summary of Pesticide Use Report Data. Various years. California Department of Pesticide Regulation. Online publication.

2. Avila-Adame, C., and Koller, W. 2003. Impact of alternative respiration and target-site mutations on responses of germinating conidia of Magnaporthe grisea to Qo-inhibiting fungicides. Pest Manag. Sci. 59:303-309.

3. Bartlett, D. W., Clough, J. M., Godwin, J. R., Hall, A. A., Hamer, M., and Parr-Dobrzanski, R. 2002. The strobilurin fungicides. Pest Manag. Sci. 58:649-662.

4. Bliss, C. I. 1935. The calculation of the dosage-mortality curve. Ann. Appl. Biol. 22:134167.
5. Brown, J. K. M., and Evans, N. 1992. Selection on responses of barley powdery mildew to morpholine and piperidine fungicides. Crop Prot. 11:449-457.

6. Chin, K. M., Chavaillaz, D., Kaesbohrer, M., Staub, T., and Felsenstein, F. G. 2001. Characterizing resistance risk of Erysiphe graminis $\mathrm{f}$. sp. tritici to strobilurins. Crop Prot. 20:87-96.

7. Chin, K. M., Wirz, M., and Laird, D. 2001. Sensitivity of Mycosphaerella fijiensis from banana to trifloxystrobin. Plant Dis. 85:12641270.

8. Dutzmann, S., Berg, D., Clausen, N. E., Kraemer, W., Kuck, K. H., Pontzen, R., Tiemann, R., and Weissmueller, J. 1996. KWG 4168: A novel foliar fungicide with a particular activity against powdery mildew. Pages 47-52 in: Brighton Crop Prot. Conf. Pests \& Diseases Vol. 1, Proc. Int. Conf. Brighton, England, UK. British Crop Protection Council (BCPC), Farnham, England.

9. Engels, A. J. G., Holub, E. F., Swart, K., and De Waard, M. A. 1998. Genetic analysis of resistance to fenpropimorph in Aspergillus niger. Curr. Genet. 33:145-150.

10. Erickson, E. O., and Wilcox, W. F. 1997. Distributions of sensitivities to three sterol demethylation inhibitor fungicides among populations of Uncinula necator sensitive and resistant to triadimefon. Phytopathology 87:784791.

11. Finney, D. J. 1971. Probit Analysis. 3rd ed. Cambridge University Press, New York.

12. Geng, S. 1997. Biometrics in Agricultural Science. Kendall/Hunt Publishing Company, Dubuque, IA.

13. Georgopoulos, S. G. 1988. Genetics and population dynamics. Pages 12-13 in: Fungicide Resistance in North America. C. J. Delp, ed. American Phytopathological Society Press, St. Paul, MN.

14. Gisi, U., Chin, K. M., Knapova, G., Küng Färber, R., Mohr, U., Parisi, S., Sierotzki, H., and Steinfeld, U. 2002. Recent developments in elucidating modes of resistance to phenylamide, DMI and strobilurin fungicides. Crop Prot. 19:863-872.

15. Gisi, U., Sierotzki, H., Cook, A., and McCaffery, A. 2002. Mechanisms influencing the evolution of resistance to Qo inhibitor fungicides. Pest Manag. Sci. 58:859-867.

16. Gubler, W. D., Ypema, H. L., Ouimette, D. G., and Bettiga, L. J. 1994. Resistance of Uncinula necator to DMI fungicides in California vines. Pages 19-25 in: Fungicide Resistance. S. Heaney, D. Slavson, D. W. Hollomon, M. Smith, P. E. Russell, and D. W. Parry, eds. British Crop Protection Council, University of Reading, UK

17. Gubler, W. D., Ypema, H. L., Ouimette, D. G., and Bettiga, L. J. 1996. Occurrence of resistance in Uncinula necator to triadimefon, myclobutanil, and fenarimol in California grapevines. Plant Dis. 80:902-909.

18. Hayashi, K., Schoonbeek, H.-J., Sugiura, H., and De Waard, M. A. 2001. Multidrug resistance in Botrytis cinerea associated with decreased accumulation of the azole fungicide oxpoconazole and increased transcription of the $\mathrm{ABC}$ transporter gene BcatrD. Pestic. Biochem. Physiol. 70:168-179.

19. Heaney, S. P. 1991. A method for examination of the sensitivity of Uncinula necator to DMI fungicides. Bull. OEPP/EPPO Bull. 21:319321.

20. Hiratani, T., and Yamaguchi, H. 1994. Crossresistance of Candida albicans to several different families of antifungals with ergosterol biosynthesis-inhibiting activity. Jpn. J. Antibiot. 47:125-128.

21. Hornik, L., Molnar, A., and Oros, G. 1988. Variations in sensitivity to benzimidazole and non-benzimidazole fungicides of genetically different benomyl resistant Fusarium-ox- ysporum strains. Acta Phytopathol. Entomol. Hung. 23:3-10.

22. Ishii, H., Fraaije, B. A., Sugiyama, T., Noguchi, K., Nishimura, K., Takeda, T., Amano, T. and Hollomon, D. W. 2001. Occurrence and molecular characterization of strobilurin resistance in cucumber powdery mildew and downy mildew. Phytopathology 91:1166-1171.

23. Karaoglanidis, G. S., and Thanassoulopoulos, C. C. 2003. Cross-resistance patterns among sterol biosynthesis inhibiting fungicides (SBIs) in Cercospora beticola. Eur. J. Plant Pathol. 109:929-934.

24. Kim, Y. S., Dixon, E. W., Vincelli, P., and Farman, M. L. 2003. Field resistance to strobilurin (QoI) fungicides in Pyricularia grisea caused by mutations in the mitochondrial cytochrome $b$ gene. Phytopathology 93:891-900.

25. Kraemer, W., Berg, D., Dutzmann, S., Etzel, W. A., Gau, W., Stelzer, U., and Weissmueller, J. 1999. Chemistry, stereochemistry, and biological properties of KWG 4168. Pestic. Sci. 55:610-614.

26. Kuck, K.-H. 1997. KWG 4168 (Spiroxamine): Baseline sensitivity and cross resistance with other fungicides. Pflanzenschutz-Nachrichten Bayer (English Ed.) 50:17-18.

27. Küng, R. 1991. Test method for examination of the sensitivity of Uncinula necator to pyrifenox. Bull. OEPP/EPPO Bull. 21:317319.

28. Küng-Färber, R. B., Chin, K. M., and Leadbitter, N. 2002. Sensitivity of Venturia inaequalis to trifloxystrobin. Pest Manag. Sci. 58:261267.

29. Leroux, P., Chapeland, F., Desbrosses, D., and Gredt, M. 2000. Patterns of cross-resistance to fungicides in Botryotinia fuckeliana (Botrytis cinerea) isolates from French vineyards. Crop Prot. 18:687-697.

30. Leroux, P., Fritz, R., Debieu, D., Albertini, C., Lanen, C., Bach, J., Gred, M., and Chapeland, F. 2002. Mechanisms of resistance to fungicides in field strains of Botrytis cinerea. Pest Manag. Sci. 58:876-888.

31. Markoglou, A. N., and Ziogas, B. N. 2002. Genetic control of resistance to the piperidine fungicide piperalin in Ustilago maydis. Eur. J. Plant Pathol. 108:21-30.

32. Markoglou, A. N., and Ziogas, B. N. 2002. SBI-fungicides: Fungicidal effectiveness and resistance in Botrytis cinerea. Phytopathol. Mediterr. 41:120-130.

33. McGrath, M. T., and Shishkoff, N. 2003. Resistance to strobilurin fungicides in Podosphaera xanthii associated with reduced control of cucurbit powdery mildew in a research field. (Abstr.) Phytopathology 93:S59.

34. McGrath, M. T., and Shishkoff, N. 2003. First report of the cucurbit powdery mildew fungus (Podosphaera xanthii) resistant to strobilurin fungicides in the United States. Plant Dis. 87:1007.

35. Nuninger-Ney, C., Schwinn, F.-J., and Staub, T. 1989. In-vitro selection of sterol biosynthesis inhibitor SBI-resistant mutants in Monilinia-fructicola Wint. Honey. Neth. J. Plant Pathol. 95(Suppl. 1):137-150.

36. Ogawa, J. M., Gubler, W. D., and Manji, B. T. 1988. Effect of sterol biosynthesis inhibitors on diseases of stone fruits and grapes in California. Pages 262-87 in: Sterol Biosynthesis Inhibitors-Pharmaceutical and Agrochemical Aspects. D. Berg and M. Plempel, eds. VCH, New York.

37. Peever, T. L., and Milgroom, M. G. 1993. Genetic correlations in resistance to sterol biosynthesis-inhibiting fungicides in Pyrenophora teres. Phytopathology. 83:1076-1082.

38. Peever, T. L., and Milgroom, M. G. 1995. Genetic correlations in resistance to morpholine and piperidine fungicides in Pyrenophora teres populations. Eur. J. Plant Pathol. 101:93-99. 
39. Reifschneider, F. J. B., and Boiteux, L. S. 1988. A vacuum-operated settling tower for inoculation of powdery mildew fungi. Phytopathology 78:1463-1465.

40. Reuveni, M. 2001. Activity of trifloxystrobin against powdery and downy mildew diseases of grapevines. Can. J. Plant Pathol. 23:52-59.

41. Salmon, E. S. 1900. A monograph of the Erysiphaceae. Mem. Torrey Bot. Club 9:1-292.

42. Sierotzki, H., Parisi, S., Steinfeld, U., Tenzer, I., Poirey, S., and Gisi, U. 2000. Mode of resistance to respiration inhibitors at the cytochrome bc1 enzyme complex of Mycosphaerella fijiensis field isolates. Pest Manag. Sci. 56:833-841.

43. Steinfeld, U., Sierotzki, H., Parisi, S. Poirey, S., and Gisi, U. 2001. Sensitivity of mitochondrial respiration to different inhibitors in Venturia inaequalis. Pest Manag. Sci. 57:787-796.
44. Trevan, J. W. 1927. The error in the determination of toxicity. Proc. R. Soc. Lond. Ser. B. Biol. Sci. 101:483-514.

45. Tukey, J. W. 1977. Exploratory Data Analysis. Addison Wesley Publishing Company, Menlo Park, CA.

46. Vanden Bossche, H., Dromer, F., Improvisi, I., Lozano-Chiu, M., Rex, J. H., and Sanglard, D. 1998. Antifungal drug resistance in pathogenic fungi. Med. Mycol. 36(Suppl. 1):119-128.

47. Vincelli, P., and Dixon, E. 2002. Resistance to QoI (strobilurin-like) fungicides in isolates of Pyricularia grisea from perennial ryegrass. Plant Dis. 86:235-240.

48. Wellmann, H., Schauz, K., and Tiemann, R. 1996. Resistance to sterol demethylation inhibitors in Ustilago maydis. III. Cross-resistance patterns and sterol analysis. Pestic. Sci. 48:239-246.
49. Wong, F. P., and Wilcox, W. F. 2002. Sensitivity to azoxystrobin among isolates of $\mathrm{Un}$ cinula necator: Baseline distribution and relationship to myclobutanil sensitivity. Plant Dis. 86:394-404.

50. Young, I. T. 1977. Proof without prejudice: Use of the Kolmogorov-Smirnov test for the analysis of histograms from flow systems and other sources. J. Histochem. Cytochem. 25:935-941.

51. Ypema, H. L., and Gubler, W. D. 1997. Longterm effect of temperature and triadimefon on proliferation of Uncinula necator: Implications for fungicide resistance and disease risk assessment. Plant Dis. 81:1187-1192.

52. Ypema, H. L., Ypema, M., and Gubler, W. D. 1997. Sensitivity of Uncinula necator to benomyl, triadimefon, myclobutanil, and fenarimol in California. Plant Dis. 81:293-297. 